\title{
$\beta$-catenin knockdown inhibits the proliferation of human glioma cells in vitro and in vivo
}

\author{
ZHONG WANG and QIANXUE CHEN \\ Department of Neurosurgery, Renmin Hospital of Wuhan University, Wuhan, Hubei 430060, P.R. China
}

Received November 5, 2014; Accepted November 18, 2015

DOI: $10.3892 /$ etm.2016.2998

\begin{abstract}
. $\beta$-catenin is a crucial oncogene that is capable of regulating cancer progression. The aim of the present study was to clarify whether $\beta$-catenin was associated with the proliferation and progress of glioma. In order to knockdown the expression of $\beta$-catenin in human U251 glioma cells, three pairs of small interfering (si)RNA were designed and synthesized and the most effective siRNA was selected and used for silencing the endogenous $\beta$-catenin, which was detected by western blot analysis and reverse transcription-quantitative polymerase chain reaction (RT-qPCR). Proliferation was subsequently detected using a methylthiazolyl-tetrazolium bromide assay and the results demonstrated that knockdown of $\beta$-catenin significantly inhibited the proliferation of U251 cells in a timeand dose-dependent manner $(\mathrm{P}<0.01)$. Cell apoptosis rate was analyzed using flow cytometry and Annexin V-fluorescein isothiocyanate/propidium iodide staining demonstrated that $\beta$-catenin siRNA significantly increased the apoptosis of U251 cells $(\mathrm{P}<0.01)$. Furthermore, the results of an in vitro scratch assay demonstrated that $\beta$-catenin silencing suppressed the proliferation of U251 cells, as compared with the control group $(\mathrm{P}<0.01)$. In vivo, $\beta$-catenin expression levels in U251 cells were significantly inhibited $(\mathrm{P}<0.01)$ following $\beta$-catenin short hairpin (sh)RNA lentiviral-vector transfection, as detected by western blot analysis and RT-qPCR. Tumorigenicity experiments demonstrated that $\beta$-catenin inhibition significantly increased the survival rate of nude mice. The results of the present study demonstrated that knockdown of $\beta$-catenin expression significantly inhibited the progression of human glioma cancer cells, in vitro and in vivo; thus suggesting that $\beta$-catenin silencing may be a novel therapy for the treatment of human glioma.
\end{abstract}

\section{Introduction}

Malignant glioma is a type of primary brain tumor of the central nervous system (1-3). Gliomas are the most common

Correspondence to: Dr Qianxue Chen, Department of Neurosurgery, Renmin Hospital of Wuhan University, 238 Jiefang Road, Wuhan, Hubei 430060, P.R. China

E-mail: chenaqianxue85@163.com

Key words: glioma cancer, $\beta$-catenin, interference, proliferation type of intracranial tumors, accounting for $\sim 50 \%$ of intracranial tumors $(4,5)$. Glioma tumor cells grow infiltratively via diffusion, therefore there are no clear boundaries, leading to unlimited proliferation and high invasiveness (6). Glioma incidence is higher in male patients, as compared with females, and is most prevalent in adults aged $30-40$ years $(7,8)$. Although significant progress has been made in the diagnosis and treatment of malignant gliomas, including surgery, radiotherapy and chemotherapy (9-11), there have been no significant improvements in patient survival and the efficacy of treatments against malignant glioma remain poor $(12,13)$. Therefore, it is necessary to identify more effective therapeutic strategies and to investigate the mechanisms associated with the development and progression of gliomas.

The Wnt/ $\beta$-catenin pathway is a key regulatory mechanism that controls developmental processes and homeostasis (14-16). Under normal circumstances, $\beta$-catenin interacts with the glycogen synthase kinase (GSK)-3 $\beta$, adenomatous polyposis (APC) and axis suppression proteins, such as Axin, to form a complex $(16,17)$. Excess $\beta$-catenin is phosphorylated by GSK-3 $\beta$ at the amino-terminal end and is subsequently degraded by the ubiquitin proteasome system. However, activation abnormal of the $\mathrm{Wnt} / \beta$-catenin pathway frequently induces various types of cancer (18). As previous studies have demonstrated, Wnts interact with Frizzled $(\mathrm{Fz})$ receptors to activate the $\mathrm{Wnt} / \beta$-catenin pathway, which stabilizes $\beta$-catenin, resulting in accumulation in the cytoplasm (19-21). The stable $\beta$-catenin is subsequently translocated into the nucleus and forms a complex with transcription factors, including $\mathrm{T}$ cell factor/lymphocyte enhancer factor (TCF/LEF); inducing the activation and expression of cell proliferation-related genes, including c-Myc and cyclin D1 (17,22).

In the present study, small interfering (si)RNA was used to investigate whether silencing of $\beta$-catenin could inhibit the proliferation of human glioma U251 cells. The apoptosis rates of U251 cells transfected with $\beta$-catenin siRNA were also investigated, with the aim of identifying novel therapeutic options for the treatment of human glioma.

\section{Materials and methods}

Cell lines, agents and antibodies. Human glioma U251 cell line was obtained from the American Type Culture Collection (Manassas, VA, USA) and cultured in Dulbecco's modified Eagle's medium supplemented with $10 \%$ fetal calf 
serum (both Hyclone; GE Healthcare Life Sciences, Logan, UT, USA) at $37^{\circ} \mathrm{C}$ in an atmosphere containing $5 \% \mathrm{CO}_{2}$. Methylthiazolyl-tetrazolium bromide (MTT) reagent was obtained from Sigma-Aldrich (St. Louis, MO, USA). Three pairs of $\beta$-catenin siRNA were designed by Jima Corporation (Shanghai, China) using Invitrogen Lipofectamine ${ }^{\circledR}$ transfection agent obtained from Thermo Fisher Scientific, Inc. (Waltham, MA, USA) to transfect U251 cells. Anti- $\beta$-catenin antibody was obtained from Abcam (Cambridge, UK). $\beta$-catenin shRNA(h) lentiviral particles (sc-29209) and control shRNA lentiviral particles-A (sc-108080) were obtained from Santa Cruz Biotechnology Inc for the animal experiments.

MTT assay. MTT assay was performed as previously described $(23,24)$. Briefly, U251 human glioma cells $\left(2 \times 10^{3}\right.$ cells/well) were seeded in 48 -well plates. Following $24 \mathrm{~h}$, cells were transfected with $\beta$-catenin siRNA and negative control siRNA, and cultured for 48, 72 or $96 \mathrm{~h}$. Subsequently, the plate was supplemented with $20 \mu$ l MTT agent $(5 \mathrm{mg} / \mathrm{ml})$ and cultured for an additional $4 \mathrm{~h}$. Finally, $200 \mu \mathrm{l}$ dimethyl sulfoxide (Sigma-Aldrich) was added and the cells were incubated for a further $15 \mathrm{~min}$ by gently siphoning off the medium. Data were tested and analyzed.

Cell transfection. Human glioma U251 cells $\left(2 \times 10^{5}\right.$ cells/well) were cultured in a 24 -well plate and, after $24 \mathrm{~h}$, were transfected with three pairs of siRNA specific for $\beta$-catenin, as designed by Jima Corporation. $\beta$-catenin siRNA was transfected using Lipofectamine ${ }^{\circledR}$ according to the manufacturer's protocol. All laboratory supplies were lacking ribonucleases. siRNAs were transfected for $48 \mathrm{~h}$ and cell lysates were subsequently prepared for western blot analysis. Endogenous levels of $\beta$-catenin were determined by western blot analysis and the most effective siRNA was chosen for interference.

Western blot analysis. Total protein was extracted using cell protein extraction reagent (AR0103; Boster Biological Technology, Ltd., Wuhan, China). Samples (15 ng in each well) were loaded and the proteins were separated by $10 \%$ sodium dodecyl sulfate-polyacrylamide gel electrophoresis at $80 \mathrm{~V}$ for $15 \mathrm{~min}$, followed by $120 \mathrm{~V}$ at $1 \mathrm{~h}$, and were subsequently transferred onto a nitrocellulose membrane (Beijing Biodee Biotechnology Co., Ltd., Beijing, China) for protein transfer at $400 \mathrm{~mA}$ for $1 \mathrm{~h}$. Following this, the membrane was blocked with Tris buffered saline with Tween 20 (TBST) supplemented with $5 \%$ bovine serum albumin for 40 min prior to incubation with rabbit anti- $\beta$-catenin $(1: 5,000 ;$ ab32572) and mouse immunoglobulin ( $\mathrm{Ig}) \mathrm{G}_{1}$ anti- $\beta$-actin (1:5,000; sc-47778; Santa Cruz Biotechnology, Inc., Dallas, TX, USA) monoclonal antibodies in TBST containing 5\% bovine serum albumin at $4^{\circ} \mathrm{C}$ overnight. The membrane was subsequently washed three times with TBST and incubated with the horseradish peroxidase-conjugated goat anti-mouse $\operatorname{IgG}(1: 2,000 ;$ ab6789) and goat anti-rabbit IgG (1:2,000; ab6721; both Abcam) secondary antibodies, respectively, for $1 \mathrm{~h}$ at room temperature. Following this, the membranes were washed three times with TBST and the bands were detected in a dark room using chemiluminescence techniques. Images were captured using a ChemiDoc MP gel imaging system (Bio-Rad Laboratories, Inc., Hercules, CA, USA). Scrambled siRNA was used as the negative control.
A
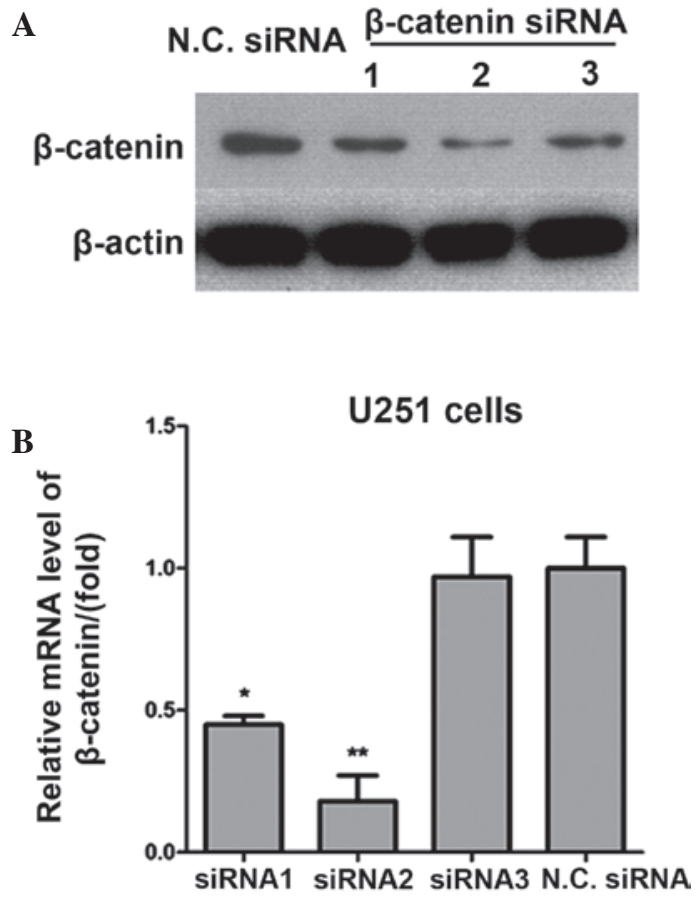

Figure 1. $\beta$-catenin-specific small interfering (si)RNA were screened for silencing of endogenous $\beta$-catenin. Briefly, U251 human glioma cells were seeded in 24-well plates. Eight hours later, three pairs of $\beta$-catenin siRNA were used to transfect the cells. After $48 \mathrm{~h}$, the cell lysates were used to detect the expression levels of $\beta$-catenin using (A) western blot analysis and (B) reverse transcription-quantitative polymerase chain reaction. Scrambled siRNA was used as the negative control (N.C.). ${ }^{*} \mathrm{P}<0.05 ;{ }^{* *} \mathrm{P}<0.01$, as compared with the N.C. siRNA group.

Reverse transcription-quantitative polymerase chain reaction $(R T-q P C R)$. In order to further investigate the effects of the three pairs of siRNAs specific for $\beta$-catenin, RT-qPCR was performed. Scrambled siRNA was used as the negative control. Total RNA was extracted from $\beta$-catenin siRNA-transfected U251 glioma cancer cells and the negative control siRNA-transfected U251 cells using TRIzol ${ }^{\circledR}$ (Takara Biotechnology Co., Ltd., Dalian, China). RNA samples were reverse transcribed using MLV-reverse transcriptase (Invitrogen; Thermo Fisher Scientific, Inc.) with random primers in a $20 \mu \mathrm{l}$ final reaction volume containing $500 \mathrm{ng}$ RNA, $0.5 \mu 1$ PrimeScript $^{\circledR}$ RT Enzyme mix, $4 \mu 1$ 5X PrimeScript ${ }^{\circledR}$ buffer and $1 \mu \mathrm{l}$ random primer.qPCR was performed to a final reaction volume of $20 \mu \mathrm{l}$ containing $1 \mu 1$ template, $10 \mu \mathrm{l} \mathrm{SYBR}{ }^{\circledR}$ Green PCR master mix (2X; Invitrogen; Thermo Fisher Scientific, Inc.), $1 \mu \mathrm{l}$ forward and reverse specific primers $(10 \mu \mathrm{m})$ and $7 \mu \mathrm{l}$ water. Primer sequences were as follows: $\beta$-actin, forward 5'-CCTGTA CGCCAACACAGTGC-3' and reverse 5'-ATACTCCTGCTT GCTGATCC-3'; and $\beta$-catenin, forward 5'-AAAATGGCA GTGCGTTTAG-3' and reverse 5'-TTTGAAGGCAGTCTG TCGTA-3'. Thermal cycling was performed on an ABI Prism 7500 Real-Time PCR system (Applied Biosystems; Thermo Fisher Scientific, Inc.) as follows: 40 cycles of $95^{\circ} \mathrm{C}$ for $30 \mathrm{sec}$ and $60^{\circ} \mathrm{C}$ for $1 \mathrm{~min}$.

Animals. A total of $30 \mathrm{male} \mathrm{BALB} / \mathrm{c}(\mathrm{nu} / \mathrm{nu})$ mice, aged 6-8 weeks old and weighing 18-20 g, were purchased from Biomed Science and Technology Co., Ltd. (Wuhan, China) and maintained in specific pathogen-free conditions. Mice 


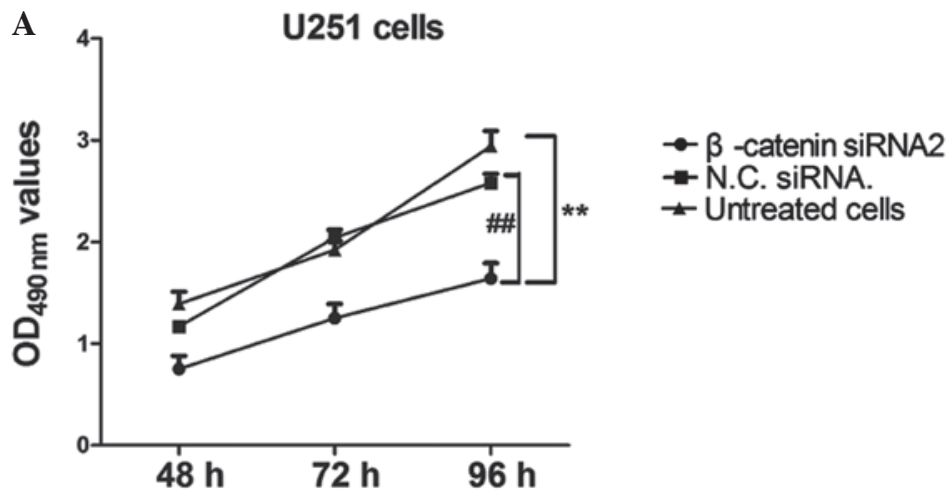

B

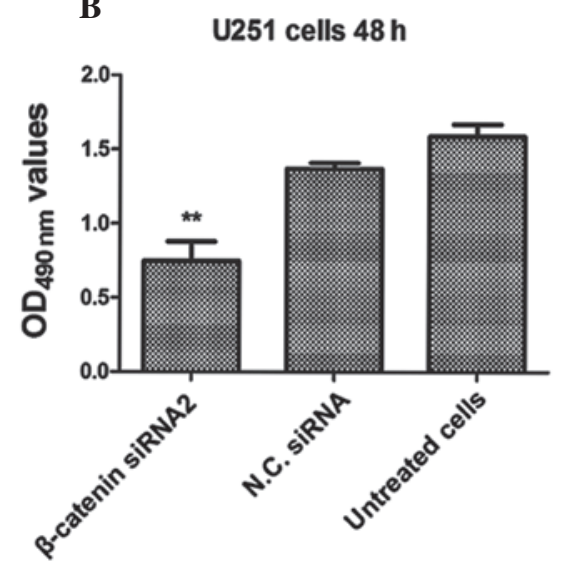

C

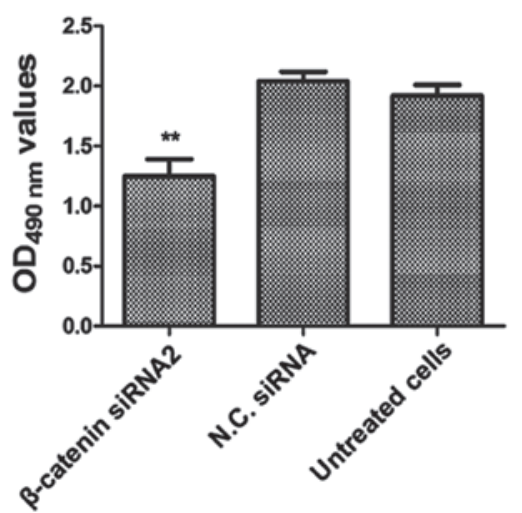

D

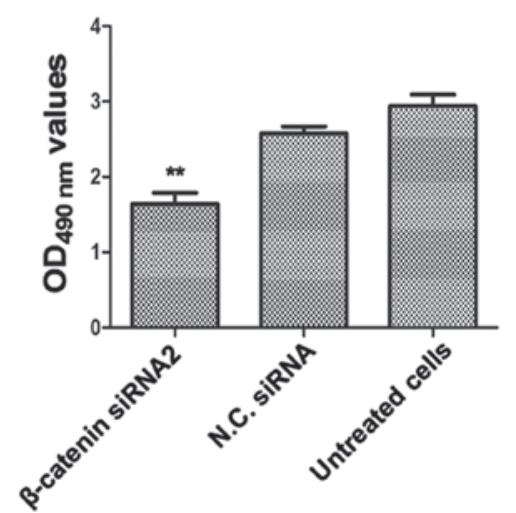

Figure 2. $\beta$-catenin siRNA inhibits the proliferation of human glioma U251 cancer cells. (A) U251 cells ( $2 \times 10^{5}$ cells/well) were seeded in 96 -well plates and, following confirmation of adherence, cells were treated with $\beta$-catenin siRNA2 or negative control siRNA for (B) 48 , (C) 72 and (D) 96 h, respectively. Untreated cells were used as negative controls. Data are presented as the mean \pm standard deviation of three independent experiments. ${ }^{* *} \mathrm{P}<0.01$ vs. the N.C. siRNA group. Si, small interfering; OD, optical density; N.C., negative control.

A
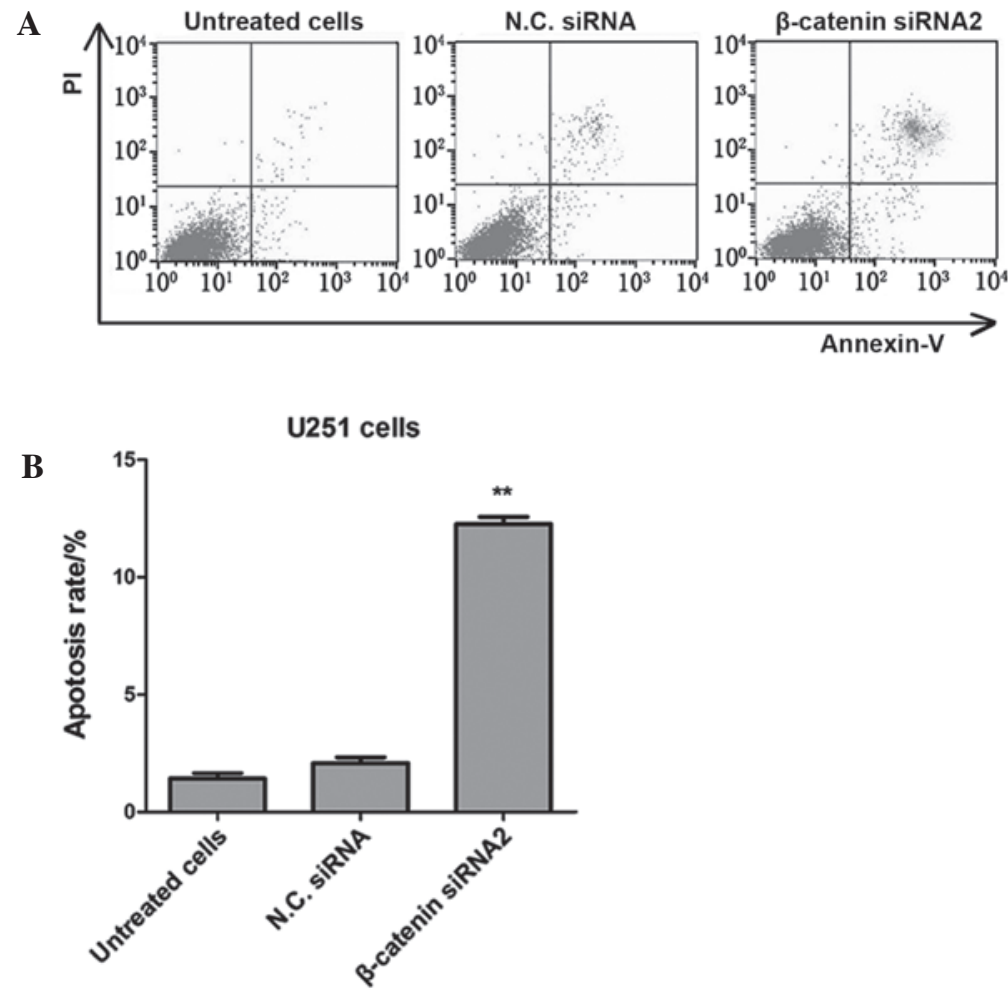

Figure 3. Silencing $\beta$-catenin using small interfering siRNA2 promotes apoptosis in human U251 glioma cancer cells. U251 cells were transfected with $\beta$-catenin siRNA2 and negative control siRNA for $48 \mathrm{~h}$. (A) Cell apoptosis was determined by Annexin V-fluorescein isothiocyanate/propidium iodide staining. (B) The apoptosis rates of $\mathrm{U} 251$ cells are presented in histograms. ${ }^{* *} \mathrm{P}<0.01$ vs. control group. Si, small interfering; N.C., negative control. 

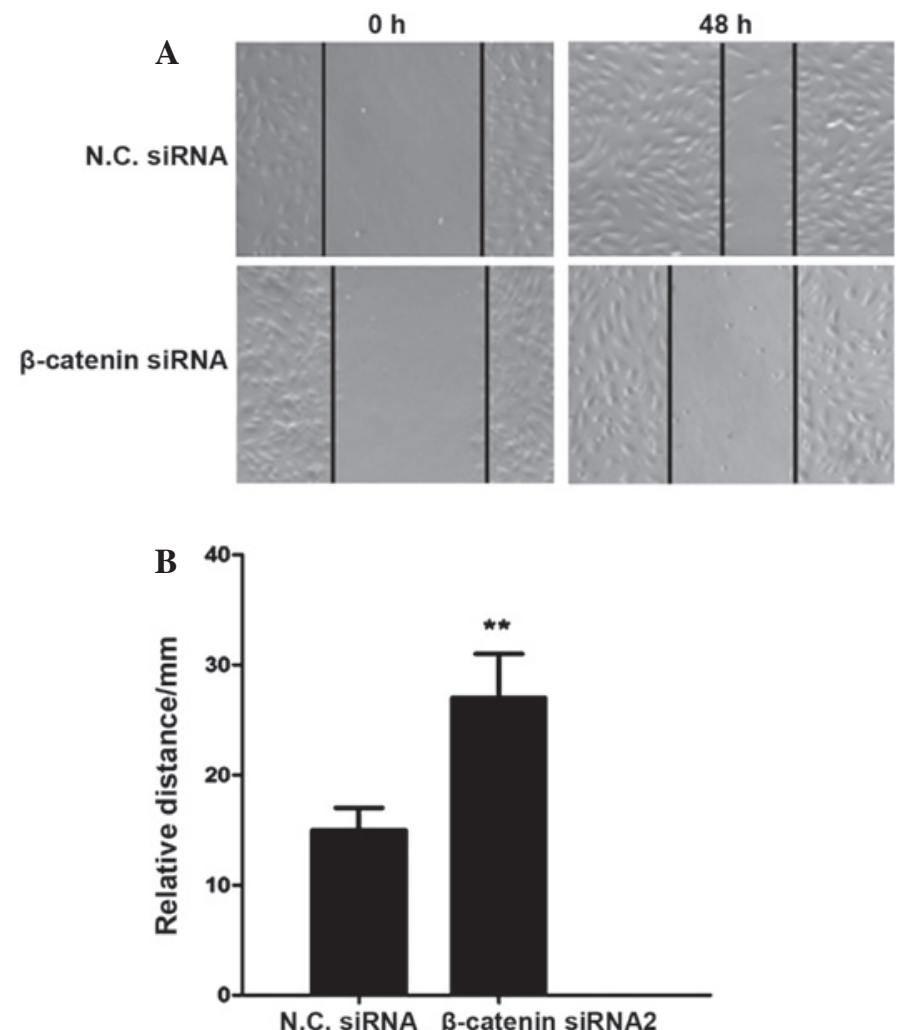

Figure 4. $\beta$-catenin siRNA2 inhibits cell invasion in U251 human glioma cells, as demonstrated by scratch assay. (A) U251 cells were transfected with $\beta$-catenin siRNA2 and negative control siRNA, and the images were captured at 0 and $48 \mathrm{~h}$ following scratching. (B) Histogram of the relative distance travelled by cells in the $\beta$-catenin siRNA and negative control groups. ${ }^{* *} \mathrm{P}<0.01$ vs. N.C. group. Si, small interfering; N.C., negative control.

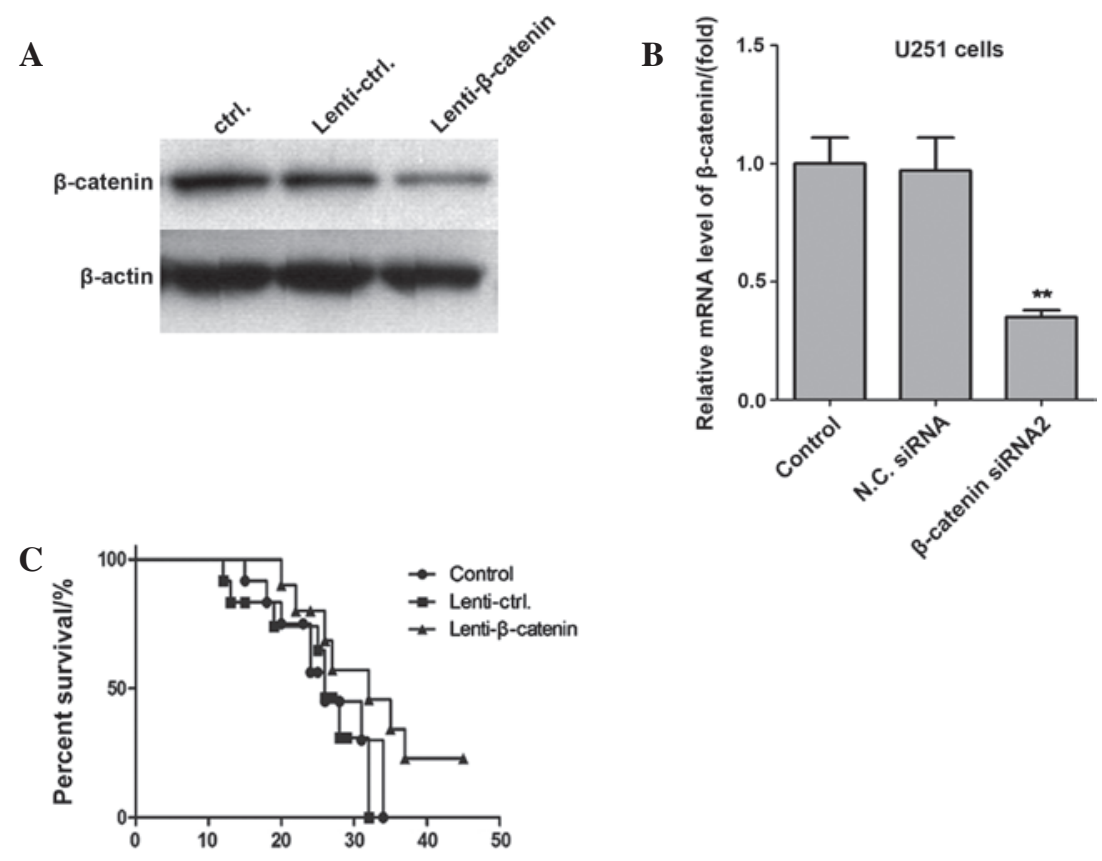

Figure 5. Knockdown of $\beta$-catenin increases survival rates in a nude mice model. U251 cells were transfected with lentiviral $\beta$-catenin shRNA and control shRNA for $48 \mathrm{~h}$, and the expression levels of $\beta$-catenin were subsequently detected by (A) western blotting analysis and (B) reverse transcription-quantitative polymerase chain reaction. Mice were challenged subcutaneously with $6 \times 10^{5}$ cells/per mouse to the flank area. (C) The survival rate was determined as follows: $100 \%$ x (number of survivors)/(number of challenged mice). ${ }^{* *} \mathrm{P}<0.01$, as compared with the N.C. siRNA group. Si, small interfering; Ctrl, control; N.C., negative control.

were randomly divided into three equal groups: Control, $\beta$-catenin short hairpin (sh)RNA and control shRNA groups. As previously described, U251 cells were transfected with lentiviral $\beta$-catenin shRNA and control shRNA for $48 \mathrm{~h}$, and the expression levels of $\beta$-catenin were subsequently detected via western blotting and RT-qPCR. The stable cell lines were 
screened using a blind screening method. Briefly, the transfected cells were plated into a 96-well plate containing diluted single cell solution (3-4 cells were cultured in every well). Cells were cultured for two weeks at $37^{\circ} \mathrm{C}$ in an atmosphere containing $5 \% \mathrm{CO}_{2}$. Once the clone had formed, western blotting was used to detect the levels of $\beta$-catenin. Cell lines with effective interfering effects were collected and used for mice injection. Control group mice were injected with untreated cells. Each group was subcutaneously injected with $6 \times 10^{5}$ cells per mouse into the flank area. Survival duration was determined as follows: Survival rate: $100 \%$ x (number of survivors)/(number of challenged mice) and the data were analyzed using GraphPad 5.0. software (GraphPad software, Inc., La Jolla, CA, USA). All protocols were approved by the Institutional Animal Care and Use Committee of Renmin Hospital (Wuhan, China) in accordance with the Declaration of Helsinki outlined by the World Medical Association.

Flow cytometry. Apoptosis rates of $\beta$-catenin siRNA-transfected U251 glioma cancer cells and negative control-siRNA transfected U251 cells were analyzed using Annexin V-propidium iodide (PI) staining, according to the manufacturer's protocol (Santa Cruz Biotechnology, Inc.). Briefly, the cells in each group were washed with phosphate-buffered saline and resuspended in binding buffer containing $10 \mathrm{mM}$ HEPES-NaOH (pH 7.4), $25 \mathrm{mM} \mathrm{CaCl}_{2}$ and $144 \mathrm{mM} \mathrm{NaCl}$. Subsequently, the cells were incubated with $0.1 \mu \mathrm{g} / \mu \mathrm{l}$ Annexin $\mathrm{V}$ and $0.05 \mu \mathrm{g} / \mu \mathrm{l}$ PI stain in the dark for 30 min on ice. In every sample, $>10,000$ cells were detected. The experiment was performed $\geq 3$ times.

Scratch assay. U251 cells were treated with negative control siRNA or $\beta$-catenin siRNA2 and were subsequently plated into a multi-well assay plate and allowed to attach, spread and form a confluent monolayer. Subsequently, a pipette tip was used to scratch the confluent monolayer in order to remove cells from a discrete area to form a cell-free zone into which cells at the edges of the wound could migrate. Cells in each group were cultured and images documenting cell migration were captured at 0 and $24 \mathrm{~h}$ following scratching using an Olympus CKX31/41 microscope (Olympus Corporation, Tokyo, Japan). Images were subsequently analyzed using ImageJ software (National Institutes of Health, Bethesda, MA, USA).

Statistical analysis. Experiments were performed in triplicate and the results were analyzed via one-way analysis of variance using SPSS 20.0 statistical software (IBM SPSS, Armonk, NY, USA). Data from the assay of U251 cell proliferation and mice survival were analyzed using GraphPad 5.0 software. Data were presented as the mean \pm standard error of the mean. $\mathrm{P}<0.01$ was considered to indicate a statistically significant difference.

\section{Results}

siRNA silencing of $\beta$-catenin. In order to knockdown the expression of $\beta$-catenin in glioma cancer cells, three pairs of siRNA specific for $\beta$-catenin were designed and their effects investigated using western blot analysis and RT-qPCR.
siRNA2 was demonstrated to be the most effective siRNA at silencing the $\beta$-catenin gene, as detected by western blot analysis (Fig. 1A). This was consistent with the results of RT-qPCR analysis (Fig. 1B). Scrambled siRNA was used as the negative control siRNA for RT-qPCR.

$\beta$-catenin siRNA2 inhibits the proliferation of human U251 glioma cells. An MTT assay was performed in order to investigate the proliferation rate of U251 cells transfected with $\beta$-catenin siRNA2. The proliferation of glioma cancer U251 cells was significantly inhibited in the $\beta$-catenin siRNA2-transfected group, as compared with the negative control group $(\mathrm{P}<0.01$; Fig. 2). Furthermore, the results demonstrated that the proliferation rate of U251 cells was markedly reduced in the $\beta$-catenin siRNA2-transfected group, as compared with the control group, in a time-dependent manner. Untreated cells and cells transfected with negative control siRNA were used as negative controls.

Silencing of $\beta$-catenin with siRNA2 promotes apoptosis of U251 glioma cells. Apoptosis rates of U251 glioma cancer cells in the $\beta$-catenin siRNA transfected group were analyzed using flow cytometry with Annexin V-fluorescein isothiocyanate (FITC)/propidium iodide (PI) dual labeling. The apoptosis rates of U251 cells were significantly elevated in the $\beta$-catenin transfected group, as compared with the untreated cells and the negative control siRNA group $(\mathrm{P}<0.01$; Fig. 3$)$. These results demonstrated that transfection with $\beta$-catenin-siRNA2 may promote the apoptosis of human glioma cancer cells.

$\beta$-catenin siRNA2 inhibits cell invasion in U251 human glioma cells. As glioma is type of malignant tumor capable of invasion and metastasis, a scratch assay was performed to determine the effects of $\beta$-catenin siRNA on cell invasion. The relative migratory distance of glioma cells was significantly reduced in the $\beta$-catenin silencing group, as compared with the negative control group $(\mathrm{P}<0.01$; Fig. 4). These results demonstrated that $\beta$-catenin siRNA may suppress the invasive activity of U251 human glioma cells.

$\beta$-catenin silencing increases survival rates in a nude mice model. In order to further define the potential efficacy of $\beta$-catenin, a lentiviral vector of $\beta$-catenin shRNA was used to evaluate its activity against the proliferation and metastasis of glioma cancer cells in a nude mice model. U251 cells were transfected with $\beta$-catenin shRNA using a lentiviral vector, and $\beta$-catenin expression levels were significantly inhibited, as determined by western blot analysis and RT-qPCR (Fig. 5). Notably, the survival rates of mice in the $\beta$-catenin knockdown group were significantly increased, as compared with the control shRNA group and control groups $(\mathrm{P}<0.01)$. Therefore, these results demonstrated that knockdown of $\beta$-catenin expression significantly inhibited the proliferation of glioma cancer cells in vivo.

\section{Discussion}

Gliomas are the most common and aggressive type of brain tumors, accounting for $\sim 50 \%$ of intracranial tumors $(4,5)$. In order to elucidate whether the expression of $\beta$-catenin affects 
the proliferation, apoptosis and invasion of glioma cells, the U251 human glioma cancer cell line was used to clarify the molecular mechanisms of human glioma cancer. Thus, we aimed to identify novel and effective methods for the prevention and treatment of advanced glioma cancer. Firstly, three pairs of siRNAs specific to $\beta$-catenin were designed and screened, and the most effective siRNA was to silence the endogenous expression of $\beta$-catenin in U251 human glioma cells. The results of the present study demonstrated that $\beta$-catenin silencing may inhibit the proliferation of U251 human glioma cells. Furthermore, the results of the in vitro scratch assay demonstrated that the proliferation of U251 cells was significantly suppressed in the cells which were transfected with $\beta$-catenin siRNA2. Therefore, the present data suggested that siRNA knockdown of $\beta$-catenin may inhibit the proliferation and migration of human glioma cancer cells.

In order to clarify the underlying mechanisms of U251 cell proliferation, Annexin V-FITC/PI staining analysis was used to investigate the apoptosis rate of $\beta$-catenin silenced cells. As hypothesized, $\beta$-catenin knockdown suppressed the proliferation of U251 cells, as compared with the control group. These data were consistent in vivo as tumorigenicity experiments demonstrated that $\beta$-catenin silencing significantly increased the survival rates of nude mice. Therefore, these results suggested that $\beta$-catenin knockdown may lead to apoptosis and death of glioma cancer cells.

In conclusion, the results of the present study clarified the role of $\beta$-catenin in the progression of human glioma cancer, which may inform novel therapeutic strategies for the treatment of malignant glioma cancer in humans.

\section{References}

1. Mamelak AN and Jacoby DB: Targeted delivery of antitumoral therapy to glioma and other malignancies with synthetic chlorotoxin (TM-601). Expert Opin Drug Deliv 4: 175-186, 2007.

2. Glass LR, Canoll P, Lignelli A, Ligon AH and Kazim M: Optic nerve glioma: Case series with review of clinical, radiologic, molecular, and histopathologic characteristics. Ophthal Plast Reconstr Surg 30: 372-376, 2014.

3. Diamond EL, Corner GW, De Rosa A, Breitbart W and Applebaum AJ: Prognostic awareness and communication of prognostic information in malignant glioma: A systematic review. J Neurooncol 119: 227-234, 2014.

4. Goodenberger ML and Jenkins RB: Genetics of adult glioma. Cancer Genet 205: 613-621, 2012.

5. Ostrom QT, Bauchet L, Davis FG, Deltour I, Fisher JL, Langer CE, Pekmezci M, Schwartzbaum JA, Turner MC, Walsh KM, et al: The epidemiology of glioma in adults: A "state of the science" review. Neurooncol 16: 896-913, 2014.

6. Englot DJ, Berger MS, Chang EF and Garcia PA: Characteristics and treatment of seizures in patients with high-grade glioma: A review. Neurosurg Clin N Am 23: 227-235, vii-viii, 2012.

7. Alexander H, Irwin C, Purdie G and Hunn M: Incidence and management of high grade glioma in Mãori and non-Mãori patients. J Clin Neurosci 17: 1144-1147, 2010.
8. Hess KR, Broglio KR and Bondy ML: Adult glioma incidence trends in the United States, 1977-2000. Cancer 101: 2293-2299, 2004.

9. Kuijlen JM, Bremer E, Mooij JJ, den Dunnen WF and Helfrich W: Review: On TRAIL for malignant glioma therapy? Neuropathol Appl Neurobiol 36: 168-182, 2010.

10. Walter F, la Fougère C, Belka $C$ and Niyazi M: Technical Issues of [(18)F]FET-PET Imaging for Radiation Therapy Planning in Malignant Glioma Patients - A Review. Front Oncol 2: 130 2012.

11. Stylli SS and Kaye AH: Photodynamic therapy of cerebral glioma - a review. Part II - clinical studies. J Clin Neurosci 13: 709-717, 2006.

12. Tobias A, Ahmed A, Moon KS and Lesniak MS: The art of gene therapy for glioma: A review of the challenging road to the bedside. J Neurol Neurosurg Psychiatry 84: 213-222, 2013.

13. Carpentier AF, Auf G and Delattre JY: CpG-oligonucleotides for cancer immunotherapy: Review of the literature and potential applications in malignant glioma. Front Biosci 8: e115-127, 2003.

14. Barker N: The canonical Wnt/beta-catenin signalling pathway. Methods Mol Biol 468: 5-15, 2008.

15. Lugli A, Zlobec I, Minoo P, Baker K, Tornillo L, Terracciano L and Jass JR: Prognostic significance of the wnt signalling pathway molecules APC, beta-catenin and E-cadherin in colorectal cancer: A tissue microarray-based analysis. Histopathology 50: 453-464, 2007.

16. Fu L, Zhang C, Zhang LY, Dong SS, Lu LH, Chen J, Dai Y, Li Y, Kong KL, Kwong DL, et al: Wnt2 secreted by tumour fibroblasts promotes tumour progression in oesophageal cancer by activation of the Wnt/ $\beta$-catenin signalling pathway. Gut 60 : 1635-1643, 2011.

17. Matono H, Tamiya S, Yokoyama R, Saito T, Iwamoto Y, Tsuneyoshi $\mathrm{M}$ and Oda Y: Abnormalities of the Wnt/ $\beta$-catenin signalling pathway induce tumour progression in sporadic desmoid tumours: Correlation between $\beta$-catenin widespread nuclear expression and VEGF overexpression. Histopathology 59: 368-375, 2011.

18. Caspi M, Zilberberg A, Eldar-Finkelman $\mathrm{H}$ and Rosin-Arbesfeld R: Nuclear GSK-3beta inhibits the canonical Wnt signalling pathway in a beta-catenin phosphorylation-independent manner. Oncogene 27: 3546-3555, 2008.

19. Weng X, Lin P, Liu F, Chen J, Li H, Huang L, Zhen C, Xu H, Liu X, Ye H and Li X: Achyranthes bidentata polysaccharides activate the $\mathrm{Wnt} / \beta$-catenin signaling pathway to promote chondrocyte proliferation. Int J Mol Med 34: 1045-1050, 2014.

20. Petersen CP and Reddien PW: Smed-betacatenin-1 is required for anteroposterior blastema polarity in planarian regeneration. Science 319: 327-330, 2008.

21. Torday JS and Rehan VK: Up-regulation of fetal rat lung parathyroid hormone-related protein gene regulatory network down-regulates the Sonic Hedgehog/Wnt/betacatenin gene regulatory network. Pediatr Res 60: 382-388, 2006.

22. Du R, Xia L, Sun S, Lian Z, Zou X, Gao J, Xie H, Fan R, Song J, Li X, et al: URG11 promotes gastric cancer growth and invasion by activation of beta-catenin signalling pathway. J Cell Mol Med 14: 621-635, 2010.

23. Bilmin K, Kopczyńska B and Grieb P: Influence of serum and albumin on the in vitro anandamide cytotoxicity toward C6 glioma cells assessed by the MTT cell viability assay: Implications for the methodology of the MTT tests. Folia Neuropathol 51: 44-50, 2013.

24. Cookson MR, Mead C, Austwick SM and Pentreath VW: Use of the MTT assay for estimating toxicity in primary astrocyte and C6 glioma cell cultures. Toxicol In Vitro 9: 39-48, 1995. 